\title{
Conspicuous colours reduce predation rates in fossorial uropeltid snakes
}

\author{
Vivek Philip Cyriac ${ }^{{ }^{\text {Corresp., }}{ }^{1}, \text { Ullasa Kodandaramaiah }^{1}}$ \\ 1 IISER-TVM Centre for Research and Education in Ecology and Evolution (ICREEE) and School of Biology, Indian Institute of Science Education and \\ Research Thiruvananthapuram, Thiruvananthapuram, Kerala, India \\ Corresponding Author: Vivek Philip Cyriac \\ Email address: vivek.philip14@iisertvm.ac.in
}

Uropeltid snakes (Family Uropeltidae) are non-venomous, fossorial snakes that are found above ground occasionally, during which time they are exposed to predation. Many species are brightly coloured, mostly on the ventral surface, but these colours are expected to have no function below the ground. Observations have shown that the cephalic resemblance (resemblance to heads) of uropeltid tails may direct attacks of predators towards the hardened tails, thereby potentially increasing handling times for predators. Experiments have also shown that predators learn to avoid prey that are nontoxic and palatable but are difficult to capture, hard to process or require long handling time when such prey advertise their unprofitability through conspicuous colours. We here postulate that uropeltid snakes use their bright colours to signal long handling times associated with attack deflection to the tails, thereby securing reduced predation from predators that can learn to associate colour with handling time. Captive chicken experiments with dough models mimicking uropeltids indicate that attacks were more common on the tail than on the head. Field experiments with uropeltid clay models show that the conspicuous colours of these snakes decrease predation rates compared to cryptic models, but a novel conspicuous colour did not confer such a benefit. Overall, our experiments provide support for our hypothesis that the conspicuous colours of these snakes reduce predation, possibly because these colours advertise unprofitability due to long handling times. 
1 TITLE: Conspicuous colours reduce predation rates in fossorial uropeltid snakes

2

3

4

(1)

(1)

Vivek Philip Cyriac $^{1 *}$ and Ullasa Kodandaramaiah ${ }^{1}$

${ }^{1}$ IISER-TVM Centre for Research and Education in Ecology and Evolution (ICREEE) and School of Biology, Indian Institute of Science Education and Research Thiruvananthapuram, Maruthamala P.O., Vithura, Thiruvananthapuram, India. 695551.

* Corresponding author: Vivek Philip Cyriac, IISER-TVM Centre for Research and Education in Ecology and Evolution (ICREEE), School of Biology, Indian Institute of Science Education and Research Thiruvananthapuram, Maruthamala P.O., Vithura, Thiruvananthapuram, India. 695551. Ph: +917593978351

Email: vivek.philip14@,iisertvm.ac.in

Authors Contributions: VPC conceived the study, designed the experiments and carried out the experiments; UK provided materials; both VPC and UK wrote the paper; both authors agree to the final version of the paper.

\section{Declaration of Conflict of Interest: none}

Funding: This work was supported by an INSPIRE Faculty Award to UK (DST/INSPIRE/04/2013/000476) and intra-mural funding from IISER Thiruvananthapuram.

(1)

(1)

(1) 


\section{Abstract}

36 Uropeltid snakes (Family Uropeltidae) are non-venomous, fossorial snakes that are found above

37 ground occasionally, during which time they are exposed to predation. Many species are brightly coloured, mostly on the ventral surface, but these colours are expected to have no function below the ground. Observations have shown that the cephalic resemblance (resemblance to heads) of uropeltid tails may direct attacks of predators towards the hardened tails, thereby potentially increasing handling times for predators. Experiments have also shown that predators learn to avoid prey that are non-toxic and palatable but are difficult to capture,hard to process or require long handling time when such prey advertise their unprofitability through conspicuous colours.

44 We here postulate that uropeltid snakes use their bright colours to signal long handling times associated with attack deflection to the tails, thereby securing reduced predation from predators that can learn to associate colour with handling time. Captive chicken experiments with dough models mimicking uropeltids indicate that attacks were more common on the tail than on the head. Field experiments with uropeltid clay models show that the conspicuous colours of these snakes decrease predation rates compared to cryptic models, but a novel conspicuous colour did not confer such a benefit. Overall, our experiments provide support for our hypothesis that the conspicuous colours of these snakes reduce predation, possibly because these colours advertise

52 unprofitability due to long handling times.

53 Keywords: Antipredatory strategies, conspicuous colourations, fossorial, handling time,

54 Uropeltidae 
62

63

64

65

66

67

68

69

\section{INTRODUCTION:}

Conspicuous colourations (colours that contrast with the background) are prevalent in the animal kingdom and have fascinated biologists for a very long time, prompting them to seek a functional explanation for such colours (Poulton, 1890; Cott, 1940; Edmunds, 1974; Cuthill et al., 2017). Such colours may be part of mate-choice or other intra-specific signals, or may be involved in predator avoidance e.g. aposematism and mimicry (Caro \& Allen, 2017). Over the last few decades, these theories have been widely tested, leading to a good understanding of bright conspicuous colours in animals (Gamberale-Stille \& Tullberg, 1999; Speed, 2001; Pfennig, Harcombe \& Pfennig, 2001; Tullberg, Merilaita \& Wiklund, 2005; Stevens, Stubbins \& Hardman, 2008).

However, the presence of conspicuous colours in many animals still remains unexplained (e.g. contrasting colours in mammals (Caro Tim, 2009), colourations in many frogs (Bordignon et al., 2018) and caecilians (Wollenberg \& Measey, 2009)) with research on new systems revealing new insights onto the role of such colourations (Rößler et al., 2019). Subterranean organisms which live in conditions devoid of light tend to have reduced vision and lose pigmentations (Culver \& Pipan, 2009). Yet, several species of fossorial snakes that spend most of their time underground exhibit bright colourations (e.g. members of the genus Cylindrophis, Anomochilus, Atractus. etc.) (Greene,1988). Colours, especially those produced via pigments, are generally used as visual stimuli for intraspecific or interspecific interactions and thought to be costly to produce, therefore the presence of bright colours in subterranean animals is thought to be adaptive (Wollenberg \& Measey, 2009). However, the role of conspicuous colouration in fossorial reptiles remains unexplored.

Uropeltid snakes are a family of fossorial snakes comprising ca. 55 species from South Asia (Cyriac \& Kodandaramaiah, 2017). Most uropeltid species are ornamented on the ventral surface with bright conspicuous colouration, with the majority possessing varying degrees of yellow while a few species (ca. 5) possess red (Fig. 1). Although these snakes spend most of their time underground, they occasionally come to the surface during the monsoons (Rajendran, 1985). Uropeltids are mostly nocturnal but can be found actively moving close to the surface during early mornings and late evenings (Rajendran, 1985) during which times they are exposed to above ground predators (Rajendran, 1985; Gans, 1986; Kumara \& Chaitra, 2001). Uropeltid 
92 snakes have characteristic morphologies adapted for burrowing into soil: a narrow head and a 93 short distinctive tail which is tapering or rounded (Smith, 1943). The tails of many species

94 95 96 97 appear obliquely cut, with hard carinate scales (supplementary material, Fig. S1). When attacked by predators, these snakes conceal their heads between their body coils and display their tails along with the conspicuously coloured ventral surface (Gans, 1986) (Fig 2). The tail in uropeltid snakes, being short and rounded, resembles the head. This cephalic resemblance was found to deflect attacks of avian predators to the reinforced tail, thus allowing the snake to escape unharmed in most cases after multiple attacks oriented towards the tail (Gans, 1986). Such defenses would also potentially increase the handling time needed for predators to capture, kill and consume the prey.

Optimal foraging theory predicts that predators should avoid prey with increased handling times, especially when prey with lower handling times are abundant alternatives (Charnov, 1976; Krebs et al., 1977). Studies suggest that predators can learn to avoid unprofitable prey that are difficult to capture (Hancox \& Allen, 1991; Pinheiro, 1996; Pinheiro et al., 2016), hard to process (Wang et al., 2018) or require long handling time (Cyriac \& Kodandaramaiah, in press) when such prey possess conspicuous colours, even if the prey are non-toxic and palatable (Mappes, Marples \& Endler, 2005). We here postulate that bright colours in uropeltid snakes reduce predation, possibly by signaling long handling times associated with attack deflection to the tails. We first show that the yellow and red ventral colourations in uropeltid snakes are conspicuous to birds, the main predators of these snakes. In experiments involving captive chickens attacking dough models resembling uropeltid snakes, we show that attacks are directed more often towards the tail than the head. In field experiments with clay models that resemble uropeltid snakes, we show that the bright yellow and red colours of wild uropeltids decrease predation by native birds. We conclude that the bright colours of these snakes reduce avian predation, and that these colours possibly play a role in advertising long handling time.

\section{MATERIALS AND METHODS}

\section{Study system and area}

We conducted our field experiment in the tea plantations of the Bombay Burma Trading Corporation (BBTC) $\left(8.52^{\circ} \mathrm{N}, 77.40^{\circ} \mathrm{E}\right.$ and $\left.8.56^{\circ} \mathrm{N}, 77.25^{\circ} \mathrm{E}\right)$ in Thirunelvelly district of Tamil 
121 Nadu, India. The BBTC tea plantations cover an area ca. $34 \mathrm{~km}^{2}$ with fragments of natural forest

122 vegetation left as windbreaks between patches of plantations. The area harbors at least five

123 species of uropeltid snakes (Rajendran, 1985) that vary in their colourations - Melanophidiumn

124 punctatum which has a bluish iridescent colour, Teretrurus $c f$. sanguineus which is black

125 dorsally and red ventrally, and three species of Uropeltis which are usually black dorsally with

126 variable amounts of yellow colouration ventrally. Within this community, we focused on two

127 species, U. liura and T. cf. sanguineus, that co-occur and are found in high abundance in the

128 BBTC tea plantations.

129 Avian visual modeling and conspicuousness against leaf litter background

130 We laid out four transects, each spanning 200m in length, in the four windbreak forest patches

131 (Kakachi-1, Kakachi-2, Cullinia forest and Manjolai). Each transect was subdivided into 25 sub-

132 transects perpendicular to the main transect at every eight meters, alternating in direction. From

133 each sub-transect, we collected leaf litter samples representing the background in which the

134 snakes are usually found. Leaf litter was obtained by randomly throwing a $30 \mathrm{~cm} \mathrm{X} 30 \mathrm{~cm}$

135 cardboard frame thrice onto the forest floor, each time collecting 10-15 leaf samples. We

136 measured the spectral reflectance measurements from five to six leaves representing the different

137 visibly identifiable shades of all species from each sub-transect. We also measured the spectral

138 reflectance of the ventral colourations of one individual each of Uropeltis liura and Teretrurus

139 cf. sanguineus using a reflectance probe connected to a xenon light source (PX-2, Ocean optics,

140 USA) and a spectrophotometer (Maya 2000, Ocean optics, USA). We took three readings each

141 on the dorsal and ventral surface of every leaf and ten readings from different locations on the

142 ventral surface of both snake species. We calculated the mean reflectance of the leaf litter for the

143 four transects and the two species of snakes after interpolating the raw reflectance values into

$1441 \mathrm{~nm}$ bins between 300 to $700 \mathrm{~nm}$.

145 We modeled the ability of birds to distinguish the colouration of the two snake species against 146 the leaf litter background using the Receptor Noise Limited (RNL) model (Vorobyev \& Osorio, 147 1998) in the R package Pavo v. 2.1.0 (Maia et al. 2019). The RNL model assumes that colour 148 vision is based on opponent interaction and models the ability to discriminate colours in relation 149 to the noise in the opponent channel. The primary predators of uropeltid snakes are terrestrial 150 birds such as junglefowl (Gallus sonneratii), spurfowls (Galloperdix spadicea and Galloperdix 
151 lunulata) and peafowl (Pavo cristatus) (Rajendran, 1985). Thus, we used the relative proportion

152 of cone types of 1:2:4:4 for domestic chickens (Gallus gallus) (Kram, Mantey \& Corbo, 2010)

153 and 0.92:1:0.81:0.54 for peafowl (Hart, 2002) representing the Violet-sensitive (VS) visual

154 system of birds to model the colour contrasts. We also modeled the colour contrasts using the

155 relative proportion of cone types of 1:0.99:0.71:0.37 for blue tits (Cyanistes caeruleus) (Hart et

156 al., 2000), which represent the UV-sensitive (UVS) visual system. The relative proportion of

157 cone types representing the short wavelength sensitive, medium wavelength sensitive, long

158 wavelength sensitive and UV sensitive cone type respectively were used with a Weber fraction

159 of 0.06 (Olsson, Lind \& Kelber, 2015) modeled under forest shade illumination. The results of

160 the RNL model are summarized as $\Delta \mathrm{S}$. When $\Delta \mathrm{S}=1$ the two stimuli are just noticeable, or 1 'Just

161 Noticeable Differences' (JND). Following Siddiqi et al. (2004), we considered a $\Delta$ S values above

1623.00 to be easily distinguishable from the background, values between 1.00 and 3.00 to be

163 indistinguishable except under optimal light conditions and values below 1.00 as a threshold for

164 the colour to be indistinguishable from the background.

165 Predation rates on snake models in field

166 To test if avian predators avoid ventral colourations of uropeltids, we prepared 500 snake models

167 using non-toxic brown pre-coloured clay (Play clay, Uday Industries ${ }^{\mathrm{TM}}$, Goregaon, India) of five

168 treatments varying in their colourations and resembling uropeltid snakes in size and shape. We

169 placed these models in the four transects (Kakachi-1, Kakachi-2, Cullinia forest and Manjolai)

170 and recorded predation rates. There were 100 models each of five treatments 1) black dorsal with

171 red ventral colouration representing Teretrurus. cf. sanguineus, 2) black dorsal with yellow

172 ventral colouration representing Uropeltis liura, 3) black dorsal with orange ventral colouration

173 representing a conspicuous novel colour not found in uropeltid snakes of the region 4)

174 completely black models and 5) completely brown models representing many of the cryptic

175 snakes in the region. We used acrylic paints (Camel Fabrica ${ }^{\mathrm{TM}}$, Mumbai, India) for the five

176 treatments. We replicated the yellow and red colours by mixing several combinations of paints,

177 measuring their reflectance spectra and modeling them according to the RNL model using avian

178 visual systems (supplementary material S1). We chose the paint combinations that produced the

179 lowest $\Delta \mathrm{S}$ values when compared with the spectral reflectance of the two snakes (see model

180 design in supplementary methods for more details). The five treatments were placed in random

PeerJ reviewing PDF | (2019:04:36324:2:0:NEW 4 Jul 2019) 
181 order in each sub-transect at two meter intervals. Models were collected after 84-86 hours and

182

183

184

185

186

187

188

189

190

191

192

193

194

195

196

197

198

199

200

201

202

203

204

205

206

207

208

209

210

avian predation experienced by the clay replicas were scored based on predation marks on the clay models (supplementary material Fig. S2). Avian predation was identified by the characteristic V-shaped, U-shaped or conical peck marks (Willink et al., 2014). We further confirmed these marks on the snake models by comparing them to images of confirmed avian attacks that we previously obtained by direct observation of jungle babblers (Turdoides striata) and indigenous domestic chickens attacking clay snake models. We conducted two predation trials, one in June 2017 and another in July 2017 with 500 models in each set (thus a total of 1000 models) during the monsoons, when uropeltid snakes are known to be active.

\section{Captive bird experiment}

To test if the cephalic resemblance of the tail of uropeltid snakes deflects attacks of birds to the tail, we analyzed data from another experiment that was designed to test whether birds could learn handling times (Cyriac \& Kodandaramaiah, in press). In this experiment, we used 26 chickens as predators, each uniquely identifiable, maintained in a small enclosure by a chicken farmer in Vithura (Kerala, India). The prey consisted of models that resemble uropeltid snakes (a tapering head and a rounded tail) made of wheat dough and brown food colour, presented on ' $\mathrm{S}$ ' shaped yellow or brown coloured paper. Chickens were first trained to enter a $100 \mathrm{~cm}$ cubical arena and feed on small dough pieces scattered randomly in the experimental arena (acclimatization phase). Once they were acclimatized to the arena, in the next phase, we randomly divided the chickens into two groups and introduced a single dough model, fixed on yellow or brown paper, placed in the center of the arena. Half of the dough models were baked and increased the handling time of the chickens to consume the baked models while the remaining half was left unbaked. One group of chickens received the baked models on yellow paper and the unbaked models on brown paper, while the other group of chickens received both models on brown paper. Thus, we expected that chicken in the colour-associated group, where baked and unbaked models were provided on different colours, would learn the associated handling time and avoid baked models while the colour-unassociated group would show no preference. All chickens underwent 10 trials, during which they received a total of 5 baked and 5 unbaked models in random order (Cyriac \& Kodandaramaiah, in press). During this experiment, we also recorded the position of the first attacks by the chickens on the models as being on the 
211 head, mid-body or the tail.

\section{Ethical note}

213 All applicable international, national, and/or institutional guidelines for the care and use of

214 animals were followed. The experimental protocol was approved by the Institutional Animal

215 Ethics Committee of Indian Institute of Science Education and Research Thiruvananthapuram.

216 The field experiments were done with the permission of Bombay Burma Trading Corporation,

217 Limited, which owns the lands. This experiment does not require clearance from any Ethics

218 committee.

\section{Analyses}

220 All analyses were carried out in R 3.3.2 (R Core Team, 2016). To test for the effect of colour and random factors on the frequency of attacks on the snake models in the field experiment, we built Generalized Linear Mixed Models (GLMM) with the five treatments as fixed factors and transect, sub-transect, model sequence and batch (supplementary material, Table S2) as random factors using a binomial logit link function using the package lme4 v. 1.1-12 (Bates et al., 2015). We compared the fit of this model with that of a null model using a likelihood ratio test. We followed the GLMM analysis by performing a post hoc test with Tukey contrasts to test for homogeneity across groups using the package multcomp v. 1.4-8 (Hothorn, Bretz \& Westfall, 2008). Further, we used the G-test using the package RVAideMemoire v. 0.9-69 (Hervé, 2014) to check for differences in the position of first attacks by captive chickens on the dough model. We first performed a G-test on the frequency of first attacks on different positions of the dough models by captive chickens against the null expectation. We then carried out a pairwise comparison between the frequency of first attacks on the head, mid-body and the tail.

\section{RESULTS}

\section{Conspicuousness against leaf litter background}

Modeling the conspicuousness of Uropeltis liura and Teretrurus $c f$. sanguineus according to avian visual systems indicate that the ventral colourations of both species are highly conspicuous 
238 for the cone densities of VS (domestic chicken and peafowl) and UVS (blue tit) visual system of

239 birds and against the average leaf litter of all transects (Table 1).

240 Predation rates on snake models in field

241 All models were recovered after 86 hours. However, many models $(\mathrm{N}=39)$ were destroyed due

242 to trampling by large mammals such as Gaur (Bos gaurus), Sambar deer (Cervus unicolor) and 243 Asian elephants (Elephas maximus), and were, therefore, excluded from the analyses. A total of

24450 models (i.e., 5\% of all models) across both predation trials were found to have potential avian

245 attacks. The GLMM analysis indicated that the number of attacks varied significantly among the

246 treatments (Fig. 3) and that the model where predation rate was affected by phenotype (i.e.

247 model colour) was significantly better than the null model where phenotype did not affect the

248 predation rate $\left(\triangle \mathrm{AIC}=16.4, X^{2}=24.402, \mathrm{P}<0.0001\right)$. The post hoc tests indicated that the 249 number of attacks on the red (Estimate $=-2.4349, \mathrm{z}=-3.371, \mathrm{P}<0.01)$ and yellow (Estimate $=$ -

$2501.7275, \mathrm{z}=-3.198, \mathrm{P}<0.05)$ models were significantly lower compared to that on the brown

251 models. Attacks on the brown models did not differ significantly from that on either black

252 (Estimate $=0.4834, \mathrm{z}=1.328, \mathrm{P}=0.65683$ ) or novel coloured (Estimate $=0.6652, \mathrm{z}=1.745, \mathrm{P}=$

253 0.38739) models. Although the models with uropeltid colouration (red and yellow) experienced

254 less predation compared to the novel models (orange), the difference was not statistically

255 significant (red models: Estimate $=-1.7697,95 \% \mathrm{CI}=-3.7821-0.2426, \mathrm{z}=-2.369, \mathrm{P}=0.11423$;

256 yellow models: Estimate $=-1.0623,95 \% \mathrm{CI}=-2.6060-0.4814, \mathrm{z}=-1.854, \mathrm{P}=0.3248$ ).

\section{Captive bird experiments}

258 A G-test on the attack position by the captive chickens on the dough models indicate that there 259 was a significant difference in the position of first attacks ( $G$-test: $\left.G_{2}=17.102, P=0.00019\right)$.

260 There were significantly higher number of attacks on the mid-body $(\mathrm{P}=0.00034)$ and on the tail $261(\mathrm{P}=0.0087)$ compared to that on the head (Fig. 4).

263 Our avian visual modeling indicates that the yellow and red ventral colourations of uropeltid 264 snakes are highly conspicuous against the leaf litter background of all four transects and that uropeltid colours are readily visible to birds with both the Violet-sensitive (VS) and UV- 
266

267

268

269

270

271

272

273

274

275

276

277

278

279

280

281

282

283

284

285

286

287

288

289

290

291

292

293

294

295

sensitive (UVS) visual systems. The field experiments indicate that clay models with the yellow and red colouration of local uropeltid snakes experience reduced avian predation compared to the brown models. However, the novel coloured models (orange) did not differ from the brown or the black ones. Thus, the results indicate that avoidance is not towards all conspicuous colours but specifically towards uropeltid colours, suggesting that colouration in uropeltid snakes may have evolved as an antipredatory defense mechanism against avian predators.

Colouration in uropeltid snakes has sometimes been attributed to coral snake mimicry (although not experimentally tested) (Rajendran, 1985). South Asian coral snakes (genus Calliophis) are venomous, semi fossorial elapids, which share similar habitats with uropeltid snakes. However, all known species of coral snakes found in India and Sri Lanka have red ventral surfaces while most species of uropeltids have varying patterns of yellow. Further, coral snakes in India are uncommon across their range (Srinivasulu, Srinivasulu \& Molur, 2014). Several theoretical models and experimental studies have suggested that Batesian mimicry generally becomes more perfect when the model is rare (Sherratt, 2002; Harper \& Pfennig, 2007; Akcali \& Pfennig, 2014). Since coral snakes are uncommon, it is expected that selection would favor high precision of coral snake mimicry, which does not seem to be the case for uropeltids. Furthermore, some uropeltids with bright colouration are found outside the range of coral snakes, making Batesian mimicry unlikely (Pfennig \& Mullen, 2010). Therefore, although coral snake mimicry cannot be completely ruled out in some species of uropeltid snakes with red ventral colourations, the Batesian mimicry hypothesis does not explain the evolution of yellow colouration present in most uropeltid snakes because would-be models are red.

Overall, our experiments suggest that the conspicuous ventral colouration in uropeltid snakes could have evolved as a warning signal towards avian predators. Given that these snakes are endemic to India and Sri Lanka, where they are protected under stringent laws, laboratory experiments with live animals were not feasible. Our experiment with captive chickens and dough models resembling uropeltid snakes show that attacks were more frequent on the tail than on the head (Fig 4). This suggests that chickens can be deceived by the cephalic resemblance of the tail and direct their attacks towards the posterior regions, rather than towards the head as many predatory birds are known to do (Smith, 1973; Curio, 1976). Such a strategy that deflects attacks to the tail would also increase the handling time required to capture, kill and consume 
296 these snakes, making them unprofitable (Humphreys \& Ruxton, 2018). Although we have not

297 specifically tested whether deflection of attacks towards the tail increases handling time in

298

299

300

301

302

303

304

305

306

307

308

309

310

311

312

313

314

315

316

317

318

319

320

321

322

323

324

325

uropeltid snakes, detailed observations on the sequence of events during predation of uropeltid snakes by junglefowls and peafowls indicate long handling time associated with deflected attacks towards the tail (Gans, 1986). Gans (1986) reported that ca. 95\% of the attacks by fowls were oriented towards the rounded tail of uropeltid snakes. He noted that the birds took between 22 to 40 minutes to consume uropeltid snakes after multiple attacks to the tail. He also reports anecdotal evidence that junglefowls and spurfowls were more hesitant to attack the brightly coloured Rhinophips drummondhayi, than the cryptic unicoloured R. philippinus. These observations provide further support for the hypothesis that diverted attacks from the vulnerable head to the tail could potentially increase handling time needed to kill and consume uropeltid snakes, which birds could learn to associate with their ventral colourations.

Startle or deimatic displays involve behaviours wherein conspicuous colours are suddenly displayed, providing prey a survival advantage (Umbers, Lehtonen \& Mappes, 2015; Umbers \& Mappes, 2015). Although there has been disagreement regarding what constitutes a deimatic display and how it differs from aposematism (Ruxton, Sherratt \& Speed, 2004; Umbers, Lehtonen \& Mappes, 2015; Umbers \& Mappes, 2015, 2016; Skelhorn, Holmes \& Rowe, 2016), there is general agreement that deimatism involves a momentary transient display of conspicuous signal (Ruxton, Sherratt \& Speed, 2004; Olofsson et al., 2012; Umbers \& Mappes, 2016) that triggers an unlearnt avoidance response in predators (Umbers et al., 2017, 2019). While uropeltid colours could also have a deimatic function, our experiments show that birds avoided uropeltid snake models that were static (pinned to the ground) and did not show any momentary display of conspicuous colourations. The snake models in our field experiment were painted such that the conspicuous colours were visible on the lateral side and thus were displayed and visible to small predators throughout the experimental duration (see supplementary Fig. S2). Further, the preferential avoidance of only uropeltid colours and not all conspicuous colours suggest that this avoidance is learnt. However, as we did not design our experiments to test for a deimatic function of uropeltid colourations, we cannot preclude the possibility that uropeltid colours could also function as a startle display.

Advertising increased handling time due to deflection of attacks would, however, be

PeerJ reviewing PDF | (2019:04:36324:2:0:NEW 4 Jul 2019) 
326 advantageous only when alternative prey are abundant and when predators do not learn to

327 recognize the deception. Repeated exposure to deflective structures and behaviours would reduce

328 the effectiveness of deceiving predators. However, although birds regularly feed on venomous

329 and non-venomous snakes (Guthrie, 1932), there is a risk associated with attacking snakes since

330 many snakes are venomous. Hence, birds tend to orient their attacks towards the portion of the

331 body with a bilateral indentation (neck) or towards the region with eye-like markings (Smith,

332 1973; Curio, 1976). The costs associated with attacking venomous snakes may prevent birds

333 from learning the cephalic resemblance of the tail in uropeltid snakes. Further, it has been shown

334 that the speed of a predator's learning varies for different traits (Chittka \& Osorio, 2007; Balogh

335 et al., 2010), especially when other prey are available in the community (Kikuchi et al., 2019).

336 For instance, animals show higher rates of learning towards colour signals than towards patterns

337 or shapes (Bain et al., 2007; Aronsson \& Gamberale-Stille, 2008, 2012a; Kazemi et al., 2014;

338 Sherratt et al., 2015). Given that colours are more salient than other cues, birds may be able to

339 associate colour with increased handling time in uropeltid snakes faster than learning the

340 cephalic resemblance of the tail. Also, deflective traits are thought to be associated with life

341 histories that reduce exposure to predators, thereby reducing the potential of learning such

342 deceptive traits (Humphreys \& Ruxton, 2018). Uropeltid snakes are highly seasonal and are

343 active above ground or near the surface during the monsoons (Rajendran, 1985) when the species

344 richness and abundance of leaf litter arthropods are high (Janzen \& Schoener, 1968; Frith \&

345 Frith, 1990; Develey \& Peres, 2000). High densities of arthropods during the wet seasons in

346 tropical regions could serve as an alternative prey base for avian predators. The short activity

347 period of uropeltid snakes would also reduce the ability of avian predators to learn to ignore

348 deflective traits.

349 Although we cannot completely rule out the possibility of Batesian mimicry in some species of

350 uropeltids, our experiments together support the hypothesis that the conspicuous colourations in

351 these snakes act as warning signals against avian predators. Our results are also consistent with

352 the novel hypothesis that conspicuous colourations in uropeltid snakes have an antipredatory

353 function and is based on advertising increased handling time associated with diverted attacks to

354 the tail. Nonetheless, given that we have not explicitly tested whether misdirected attacks to the

355 tail increases the handling time of these snakes, we acknowledge that a functional relationship

356 between the colouration and tail shape and its role in reducing predation cannot be ruled out. For 
357 instance, many species of uropeltid snakes possess yellow or red blotches or stripes on the lateral

358 sides of the tail (Fig. 2B; supplementary material, Fig. S1D \& S1F) that could divert the attention

359 of predators and deflect attacks towards the tail. However, further experiments would be required

360 to determine whether colouration and tail shape interact to divert attacks and how this would

361 influence handling time and learning in predators.

362 Antipredatory defenses involving both deflection of attacks and warning colourations may not be 363 restricted to Uropeltidae. Fossorial reptiles, especially snakes, tend to have long trunks and short 364 rounded tails (Wiens \& Slingluff, 2001; Wiens, Brandley \& Reeder, 2006), the latter of which 365 many species display to divert attacks from the head to the tail (Greene, 1973, 1979, 1988; Han 366 \& Young, 2018). Several fossorial snakes (e.g., Cylindrophidae, Anomochilidae, Anillidae, 367 Atractaspinae, Aparallactinae) exhibit conspicuous colourations potentially having a similar

368 function as in uropeltid snakes. However, how widespread such strategies are across animals 369 needs to be evaluated.

\section{CONCLUSION}

371 Our study highlights how combinations of defensive strategies such as deflection, which increases handling time, and warning signals, could function synergistically against predation.

373 Different antipredatory strategies need not be mutually exclusive and can interact depending on 374 the predators' visual perception (Stevens, 2007). For instance, it has been shown that patterns 375 with strong internal contrast can increase conspicuousness (Aronsson \& Gamberale-Stille, 376 2012b) but can also generate a disruptive effect (Stevens \& Cuthill, 2006; Schaefer \& Stobbe, 377 2006). Warning colourations can also be distance dependent, providing camouflage at greater 378 distances while being conspicuous at close proximity (Tullberg, Merilaita \& Wiklund, 2005; 379 Barnett, Cuthill \& Scott-Samuel, 2018). For instance, the contrasting bands of coral snake 380 mimics and the zig-zag pattern of many vipers act as warning signals to predators (Pfennig, 381 Harcombe \& Pfennig, 2001; Wüster et al., 2004; Niskanen \& Mappes, 2005) but these bands can 382 also function in camouflage during motion through the flicker-fusion effect (Lindell \& Forsman, 1996; Titcomb, Kikuchi \& Pfennig, 2014). Despite considerable advances in our understanding

384 of animal defenses, we are yet to completely understand how different strategies interact with 385 each other and further experiments are necessary to understand under what conditions such 386 interactions are advantageous against predation. 
387

388

389

390

391

392

393

394

395

396

397

398

399

400

401

402

403

404

405

406

407

408

409

410

411

412

\section{ACKNOWLEDGMENTS}

We thank Umesh P. K. and BBTC tea estates, Manjolai for allowing us to carry out our field experiments in their tea plantations. We thank John Endler for his comments on an early draft of the manuscript. We thank David Gower for his discussions on uropeltid snakes. We thank Almut Kelber and Balamurali G.S. for the discussions on avian visual models; Udita Bansal, Harshad Mayekar, Sairandhri Lapalikar, Ashish Nerlekar, Rishiddh Javery, Alex Johny, Sreejit Allipra, Gopal Murali, Gayatri Kartha, Amal Reji, Divya P.S., Midhun Krishna, Meenakshi Jyothis, Maria Babu, Varun Kher, Jewel Johnson and Reshnu Raj for assisting with preparations of the snake models; Umesh P.K., John, Alex Johny, Udita Bansal, Sreejit Allipra, Varun Kher and Jayasooryan C.S. for assisting during fieldwork in BBTC. We also thank Nawaf Abdul Majeed and Rohit Anand for their help with preparing the dough models and conducting the captive chicken experiments. We thank Umesh P.K. for images of the ventral colouration of uropeltid snakes.

\section{REFERENCES}

Akcali CK, Pfennig DW. 2014. Rapid evolution of mimicry following local model extinction. Biology letters 10:20140304.

Aronsson M, Gamberale-Stille G. 2008. Domestic chicks primarily attend to colour, not pattern, when learning an aposematic coloration. Animal Behaviour 75:417-423.

Aronsson M, Gamberale-Stille G. 2012a. Colour and pattern similarity in mimicry: evidence for a hierarchical discriminative learning of different components. Animal Behaviour $84: 881-887$.

Aronsson M, Gamberale-Stille G. 2012b. Evidence of signaling benefits to contrasting internal color boundaries in warning coloration. Behavioral Ecology 24:349-354.

Bain RS, Rashed A, Cowper VJ, Gilbert FS, Sherratt TN. 2007. The key mimetic features of hoverflies through avian eyes. Proceedings of the Royal Society B: Biological Sciences 274:1949-1954. 
413 Balogh ACV, Gamberale-Stille G, Tullberg BS, Leimar O. 2010. Feature theory and the two-step

414

415

416

417

418

419

420

421

422

423

424

425

426

427

428

429

430

431

432

433

434

hypothesis of Müllerian mimicry evolution. Evolution: International Journal of Organic Evolution 64:810-822.

Barnett JB, Cuthill IC, Scott-Samuel NE. 2018. Distance-dependent aposematism and camouflage in the cinnabar moth caterpillar (Tyria jacobaeae, Erebidae). Royal Society Open Science 5:171396. DOI: 10.1098/rsos.171396.

Bates D, Maechler M, Bolker B, Walker S. 2015. Ime4: Linear mixed-effects models using Eigen and S4. R package version 1.1-7. 2014.

Bordignon DW, Caorsi VZ, Colombo P, Abadie M, Brack IV, Dasoler BT, Borges-Martins M. 2018. Are the unken reflex and the aposematic colouration of Red-Bellied Toads efficient against bird predation? PloS one 13:e0193551.

Caro T, Allen WL. 2017. Interspecific visual signalling in animals and plants: a functional classification. Philosophical Transactions of the Royal Society B: Biological Sciences $372: 20160344$.

Caro Tim. 2009. Contrasting coloration in terrestrial mammals. Philosophical Transactions of the Royal Society B: Biological Sciences 364:537-548. DOI: 10.1098/rstb.2008.0221.

Charnov EL. 1976. Optimal foraging: attack strategy of a mantid. The American Naturalist 110:141-151.

Chittka L, Osorio D. 2007. Cognitive dimensions of predator responses to imperfect mimicry. PLoS Biology 5:e339.

Cott HB. 1940. Adaptive coloration in animals. Methuen; London.

Culver DC, Pipan T. 2009. The biology of caves and other subterranean habitats. OUP Oxford. 
435 Curio E. 1976. The ethology of predation. Zoophysiology and ecology (Vol. 7). Berlin, New

$436 \quad$ York: Springer-Verlag (pp. x, 250 p.).

437 Cuthill IC, Allen WL, Arbuckle K, Caspers B, Chaplin G, Hauber ME, Hill GE, Jablonski NG,

438 Jiggins CD, Kelber A. 2017. The biology of color. Science 357:eaan0221.

439 Cyriac VP, Kodandaramaiah U. 2017. Paleoclimate determines diversification patterns in the

440 fossorial snake family Uropeltidae Cuvier, 1829. Molecular Phylogenetics and Evolution

441 116:97-107. DOI: https://doi.org/10.1016/j.ympev.2017.08.017.

442 Cyriac VP, Kodandaramaiah U. Don't waste your time: Conspicuous colouration as a signal of

443 increased handling time. Evolutionary Ecology (in press).

444 Develey PF, Peres CA. 2000. Resource seasonality and the structure of mixed species bird flocks 445 in a coastal Atlantic forest of southeastern Brazil. Journal of Tropical Ecology 16:33-53.

446 Edmunds M. 1974. Defence in animals: a survey of anti-predator defences. Longman Publishing $447 \quad$ Group.

448 Frith D, Frith C. 1990. Seasonality of litter invertebrate populations in an Australian upland $449 \quad$ tropical rain forest. Biotropica:181-190.

450 Gamberale-Stille G, Tullberg BS. 1999. Experienced chicks show biased avoidance of stronger

451 signals: an experiment with natural colour variation in live aposematic prey. Evolutionary

$452 \quad$ Ecology 13:579-589.

453 Gans C. 1986. Automimicry and batesian mimicry in uropeltid snakes: pigment pattern, 454 proportions and behavior. J Bombay Nat Hist Soc 83:152-158.

455 Greene HW. 1973. Defensive tail display by snakes and amphisbaenians. Journal of 456 Herpetology:143-161. 
457 Greene HW. 1979. Behavioral convergence in the defensive displays of snakes. Experientia $458 \quad 35: 747-748$.

459 Greene HW. 1988. Antipredator mechanisms in reptiles. Biology of the Reptilia 16:1-152.

460 Guthrie JE. 1932. Snakes versus birds; birds versus snakes. The Wilson Bulletin 44:88-113.

461 Han D, Young BA. 2018. The rhinoceros among Serpents: Comparative anatomy and 462 experimental biophysics of Calabar burrowing python (Calabaria reinhardtii) skin. $463 \quad$ Journal of morphology 279:86-96.

464 Hancox AP, Allen JA. 1991. A simulation of evasive mimicry in the wild. Journal of Zoology 465 223:9-13.

466

467

468

469

470

471

472

473

474

475

476

477

478

Harper GR, Pfennig DW. 2007. Mimicry on the edge: why do mimics vary in resemblance to their model in different parts of their geographical range? Proceedings of the Royal Society of London B: Biological Sciences 274:1955-1961.

Hart NS. 2002. Vision in the peafowl (Aves: Pavo cristatus). Journal of Experimental Biology 205:3925-3935.

Hart NS, Partridge JC, Cuthill IC, Bennett ATD. 2000. Visual pigments, oil droplets, ocular media and cone photoreceptor distribution in two species of passerine bird: the blue tit (Parus caeruleus L.) and the blackbird (Turdus merula L.). Journal of Comparative Physiology A 186:375-387.

Hervé M. 2014. RVAideMemoire: Diverse Basic Statistical and Graphical Functions, Version 0.9-52.

Hothorn T, Bretz F, Westfall P. 2008. Simultaneous Inference in General Parametric Models. Biometrical Journal 50:346-363. DOI: 10.1002/bimj.200810425. 
479 Humphreys RK, Ruxton GD. 2018. What is known and what is not yet known about deflection

480

481

482

483

484

485

486

487

488

489

490

491

492

493

494

495

496

497

498

499

of the point of a predator's attack. Biological Journal of the Linnean Society 123:483495.

Janzen DH, Schoener TW. 1968. Differences in insect abundance and diversity between wetter and drier sites during a tropical dry season. Ecology 49:96-110.

Kazemi B, Gamberale-Stille G, Tullberg BS, Leimar O. 2014. Stimulus salience as an explanation for imperfect mimicry. Current Biology 24:965-969.

Kikuchi DW, Dornhaus A, Gopeechund V, Sherratt TN. 2019. Signal categorization by foraging animals depends on ecological diversity. eLife 8:e43965.

Kram YA, Mantey S, Corbo JC. 2010. Avian cone photoreceptors tile the retina as five independent, self-organizing mosaics. PloS one 5:e8992.

Krebs JR, Erichsen JT, Webber MI, Charnov EL. 1977. Optimal prey selection in the great tit (Parus major). Animal Behaviour 25:30-38.

Kumara HN, Chaitra MS. 2001. Uropeltid snakes and their predators. Journal of the Bombay Natural History Society 98:288-289.

Lindell LE, Forsman A. 1996. Sexual dichromatism in snakes: support for the flicker-fusion hypothesis. Canadian Journal of Zoology 74:2254-2256. DOI: 10.1139/z96-256.

Maia R, Gruson H, Endler JA, White TE. pavo 2: new tools for the spectral and spatial analysis of colour in R. Methods in Ecology and Evolution 0. DOI: 10.1111/2041-210X.13174.

Mappes J, Marples N, Endler JA. 2005. The complex business of survival by aposematism. Trends in Ecology \& Evolution 20:598-603.

Peer) reviewing PDF | (2019:04:36324:2:0:NEW 4 Jul 2019) 
500 Niskanen M, Mappes J. 2005. Significance of the dorsal zigzag pattern of Vipera latastei 501 gaditana against avian predators. Journal of Animal Ecology 74:1091-1101. DOI:

502 10.1111/j.1365-2656.2005.01008.x.

503

504

505

506

507

508

509

510

511

512

513

514

515

516

517

518

519

520

521

Olofsson M, Eriksson S, Jakobsson S, Wiklund C. 2012. Deimatic display in the European swallowtail butterfly as a secondary defence against attacks from great tits. PLoS One 7:e47092.

Olsson P, Lind O, Kelber A. 2015. Bird colour vision: behavioural thresholds reveal receptor noise. Journal of Experimental Biology 218:184-193.

Pfennig DW, Harcombe WR, Pfennig KS. 2001. Frequency-dependent Batesian mimicry. Nature 410:323. DOI: 10.1038/35066628.

Pfennig DW, Mullen SP. 2010. Mimics without models: causes and consequences of allopatry in Batesian mimicry complexes. Proceedings of the Royal Society B: Biological Sciences 277:2577-2585.

Pinheiro CE. 1996. Palatablility and escaping ability in Neotropical butterflies: tests with wild kingbirds (Tyrannus melancholicus, Tyrannidae). Biological Journal of the Linnean Society 59:351-365.

Pinheiro CEG, Freitas AVL, Campos VC, DeVries PJ, Penz CM. 2016. Both palatable and unpalatable butterflies use bright colors to signal difficulty of capture to predators. Neotropical entomology 45:107-113.

Poulton EB. 1890. The colours of animals: their meaning and use, especially considered in the case of insects. K. Paul, Trench, Trübner \& Company.

Rajendran MV. 1985. Studies in uropeltid snakes. Madurai: Madurai Kamaraj University. 
522 Rößler DC, Lötters S, Mappes J, Valkonen JK, Menin M, Lima AP, Pröhl H. 2019. Sole

523 coloration as an unual aposematic signal in a Neotropical toad. Scientific reports $5249: 1128$.

525 Ruxton GD, Sherratt TN, Speed MP. 2004. Avoiding attack: the evolutionary ecology of crypsis, 526 warning signals and mimicry. Oxford University Press.

527 Schaefer HM, Stobbe N. 2006. Disruptive coloration provides camouflage independent of 528 background matching. Proceedings. Biological Sciences 273:2427-2432. DOI: 10.1098/rspb.2006.3615.

530

531

532

533

534

535

536

537

538

539

540

541

542

Sherratt TN. 2002. The evolution of imperfect mimicry. Behavioral Ecology 13:821-826.

Sherratt TN, Whissell E, Webster R, Kikuchi DW. 2015. Hierarchical overshadowing of stimuli and its role in mimicry evolution. Animal behaviour 108:73-79.

Siddiqi A, Cronin TW, Loew ER, Vorobyev M, Summers K. 2004. Interspecific and intraspecific views of color signals in the strawberry poison frog Dendrobates pumilio. Journal of Experimental Biology 207:2471-2485.

Skelhorn J, Holmes GG, Rowe C. 2016. Deimatic or aposematic? Animal Behaviour 113:e1-e3.

Smith MA. 1943. The Fauna of British India: Reptilia and Amphibia, including the whole of the Indo-Chinese region. Serpentes. Vol. III. Taylor and Francis, London.

Smith SM. 1973. A study of prey-attack behaviour in young loggerhead shrikes, Lanius ludovicianus L. Behaviour 44:113-140.

Speed MP. 2001. Can receiver psychology explain the evolution of aposematism? Animal Behaviour 61:205-216. 
543 Srinivasulu C, Srinivasulu B, Molur S. 2014. The Status and Distribution of Reptiles in the $544 \quad$ Western Ghats, India: Conservation Assessment and Management Plan (CAMP). 545 Wildlife Information Liaison Development Society.

546 Stevens M. 2007. Predator perception and the interrelation between different forms of protective 547 coloration. Proceedings of the Royal Society of London B: Biological Sciences 274:14571464.

549

550

551

552

553

554

555

556

557

558

559

560

561

562

563

564 565

Stevens M, Cuthill IC. 2006. Disruptive coloration, crypsis and edge detection in early visual processing. Proceedings of the Royal Society B: Biological Sciences 273:2141-2147. DOI: $10.1098 / \mathrm{rspb} .2006 .3556$.

Stevens M, Stubbins CL, Hardman CJ. 2008. The anti-predator function of 'eyespots' on camouflaged and conspicuous prey. Behavioral Ecology and Sociobiology 62:1787.

Titcomb GC, Kikuchi DW, Pfennig DW. 2014. More than mimicry? Evaluating scope for flicker-fusion as a defensive strategy in coral snake mimics. Current Zoology 60:123130. DOI: $10.1093 /$ czoolo/60.1.123.

Tullberg BS, Merilaita S, Wiklund C. 2005. Aposematism and crypsis combined as a result of distance dependence: functional versatility of the colour pattern in the swallowtail butterfly larva. Proceedings of the Royal Society of London B: Biological Sciences 272:1315-1321.

Umbers KD, De Bona S, White TE, Lehtonen J, Mappes J, Endler JA. 2017. Deimatism: a neglected component of antipredator defence. Biology letters 13:20160936.

Umbers KD, Lehtonen J, Mappes J. 2015. Deimatic displays. Current Biology 25:R58-R59.

Umbers KD, Mappes J. 2015. Postattack deimatic display in the mountain katydid, Acripeza reticulata. Animal behaviour 100:68-73. 
566 Umbers KD, Mappes J. 2016. Towards a tractable working hypothesis for deimatic displays. 567 Animal behaviour 113:e5-e7.

568 Umbers KD, White TE, De Bona S, Haff T, Ryeland J, Drinkwater E, Mappes J. 2019. The

569 protective value of a defensive display varies with the experience of wild predators.

$570 \quad$ Scientific reports 9:463.

571 Vorobyev M, Osorio D. 1998. Receptor noise as a determinant of colour thresholds.

572 Proceedings. Biological Sciences 265:351-358. DOI: 10.1098/rspb.1998.0302.

573 Wang L-Y, Huang W-S, Tang H-C, Huang L-C, Lin C-P. 2018. Too hard to swallow: a secret

574 secondary defence of an aposematic insect. The Journal of Experimental Biology 221.

575 DOI: $10.1242 / \mathrm{jeb} .172486$.

576 Wiens JJ, Brandley MC, Reeder TW. 2006. Why does a trait evolve multiple times within a

577 clade? Repeated evolution of snakelike body form in squamate reptiles. Evolution

$578 \quad 60: 123-141$.

579 Wiens JJ, Slingluff JL. 2001. How lizards turn into snakes: a phylogenetic analysis of body-form $580 \quad$ evolution in anguid lizards. Evolution 55:2303-2318.

581 Willink B, García-Rodríguez A, Bolaños F, Pröhl H. 2014. The interplay between multiple 582 predators and prey colour divergence. Biological Journal of the Linnean Society $583 \quad 113: 580-589$. DOI: 10.1111/bij.12355.

584 Wollenberg KC, Measey CJ. 2009. Why colour in subterranean vertebrates? Exploring the 585 evolution of colour patterns in caecilian amphibians. Journal of Evolutionary Biology $586 \quad 22: 1046-1056$.

587 Wüster W, Allum CS, Bjargardóttir IB, Bailey KL, Dawson KJ, Guenioui J, Lewis J, McGurk J, 588 Moore AG, Niskanen M. 2004. Do aposematism and Batesian mimicry require bright colours? A 
589 test, using European viper markings. Proceedings of the Royal Society of London B: Biological 590 Sciences 271:2495-2499. 


\section{Table $\mathbf{1}$ (on next page)}

Modeling the conspicuousness of ventral colouration in Uropeltis liura and Teretrurus cf. sanguineus against leaf background for different avian predators of the four transects in BBTC tea plantation.

$\Delta S$ values $>3.00$ are considered as easily distinguishable, values between 1.00 and 3.00 are distinguishable only under optimal light conditions and values $<1.00$ are indistinguishable from the background. 
1 Table 1

\begin{tabular}{|c|c|c|c|c|c|c|}
\hline Transect & $\begin{array}{c}\text { Avian } \\
\text { Predator }\end{array}$ & Kakachi-1 & Kakachi-2 & Cullinia & Manjolai & Mean \pm SD \\
\hline \multirow{3}{*}{$\begin{array}{l}\text { Uropeltis } \\
\text { liura }\end{array}$} & $\begin{array}{l}\text { Domestic } \\
\text { chicken }\end{array}$ & 8.8676 & 9.1886 & 7.3817 & 6.8744 & $7.95 \pm 1.25$ \\
\hline & Peafowl & 10.9248 & 11.6484 & 9.0312 & 8.6232 & $10.06 \pm 1.46$ \\
\hline & Blue tit & 31.6323 & 37.6373 & 31.7853 & 28.9963 & $32.51 \pm 3.65$ \\
\hline \multirow{3}{*}{$\begin{array}{l}\text { Teretrurus cf. } \\
\text { sanguineus }\end{array}$} & $\begin{array}{l}\text { Domestic } \\
\text { chicken }\end{array}$ & 6.5345 & 7.4539 & 5.3492 & 5.5873 & $6.23 \pm 0.96$ \\
\hline & Peafowl & 9.1048 & 10.3385 & 7.4867 & 7.7093 & $8.66 \pm 1.33$ \\
\hline & Blue tit & 37.8320 & 44.1488 & 38.0672 & 35.5731 & $38.90 \pm 3.67$ \\
\hline
\end{tabular}

2 


\section{Figure 1}

Ventral colouration in different species of uropeltid snakes.

(A) Melanophidium punctatum. (B) Teretrurus of sanguineus from BBTC tea plantations. (C) Plectrurus guentheri. (D) Uropeltis liura from BBTC tea plantations. (E) Uropeltis maculata. (F) Uropeltis sp. (G) Uropeltis sp. from BBTC tea plantations. $(\mathrm{H})$ Uropeltis sp. from BBTC tea plantations. Photo credit: (A), (G), (H) Umesh P.K. and (B) - (F) Vivek Philip Cyriac
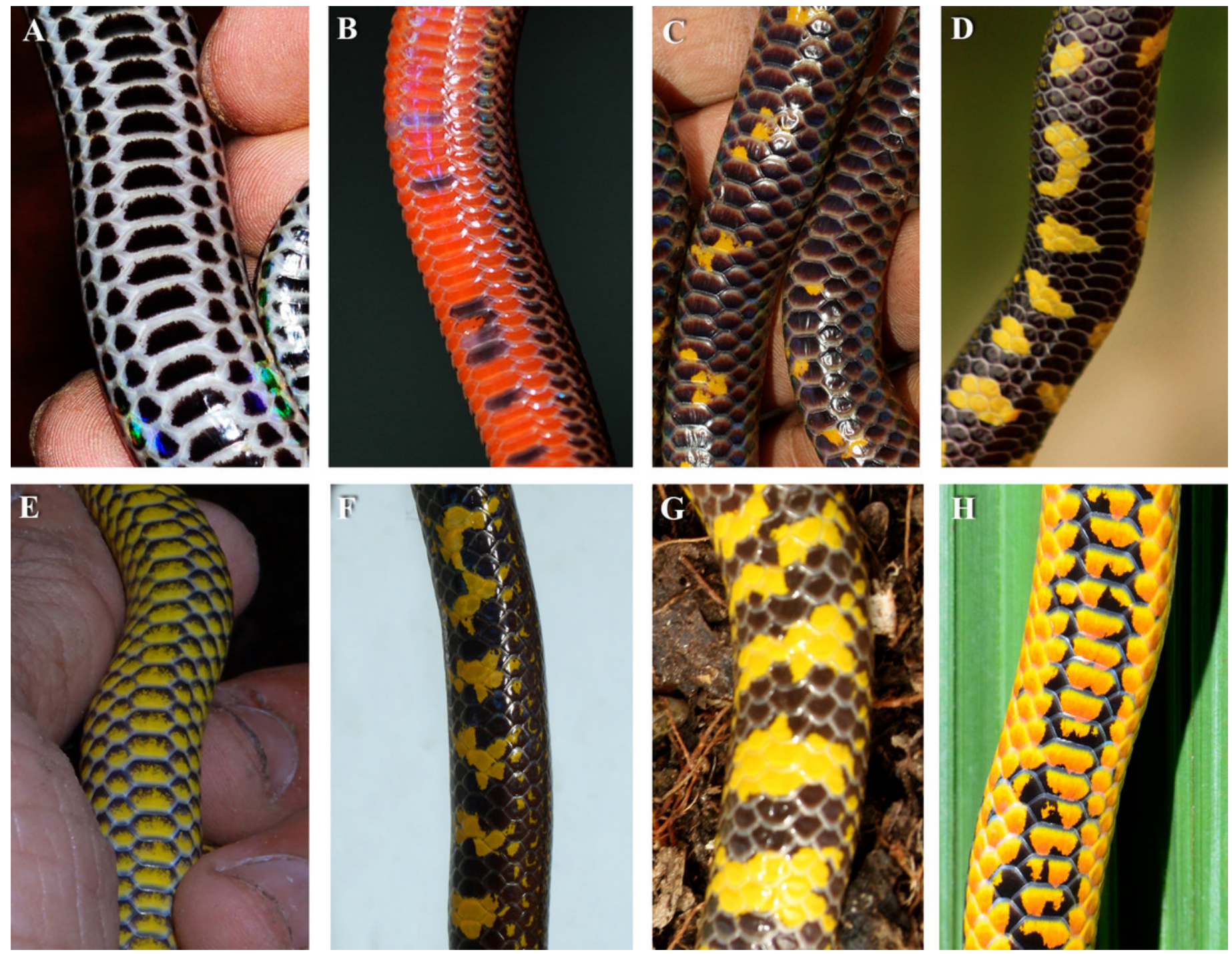


\section{Figure 2}

Tail display in uropeltid snakes.

(A) Uropeltis cf. ellioti coiled with only the tail visible. (B) U. cf. ellioti displaying the tail which is laterally lined by a thick yellow band. (C) U. cf. arcticeps displaying the tail and hiding the head under its coils. Photo credit: Vivek Philip Cyriac
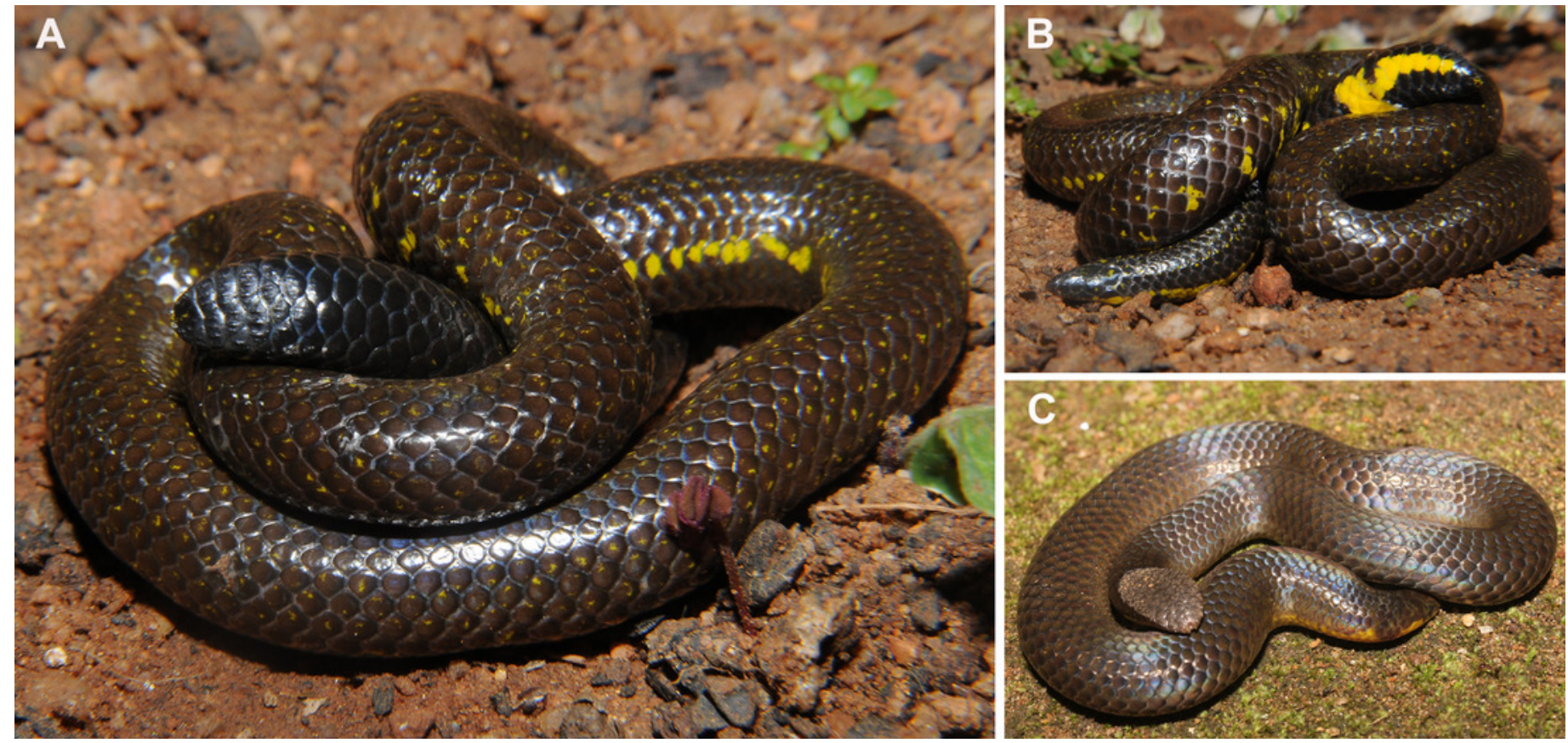


\section{Figure 3}

Predation rates on snake models from field trials.

Number of attacks by avian predators on different snake models placed in the four transects in the BBTC tea plantations. Representative photographs of models of the five treatments (completely brown, completely black, black and yellow, black and red, and black and novel coloured) are shown above the respective bars. Numbers of asterisks indicate significance levels $(* \leq 0.05, * *<0.01, * * *<0.001)$ between treatments based on a Tukey post hoc tests. 


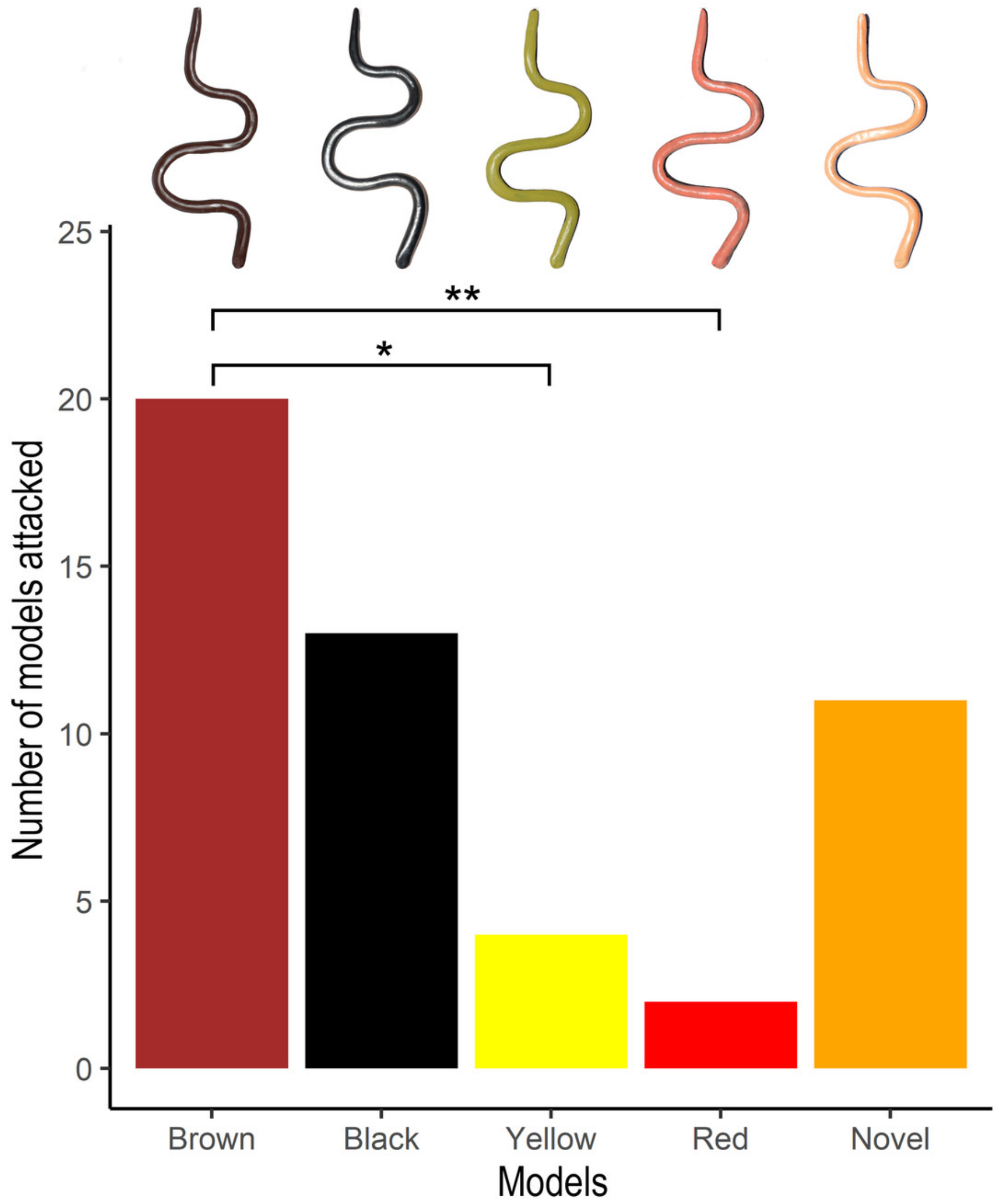




\section{Figure 4}

Position of first attacks by captive chickens on edible dough models.

(A) Frequency of first attacks oriented towards different positions of the prey by captive chickens. (B) Dough model indicating the head, mid-body and tail region where the attacks were oriented. $P$ value is based on a G-test.
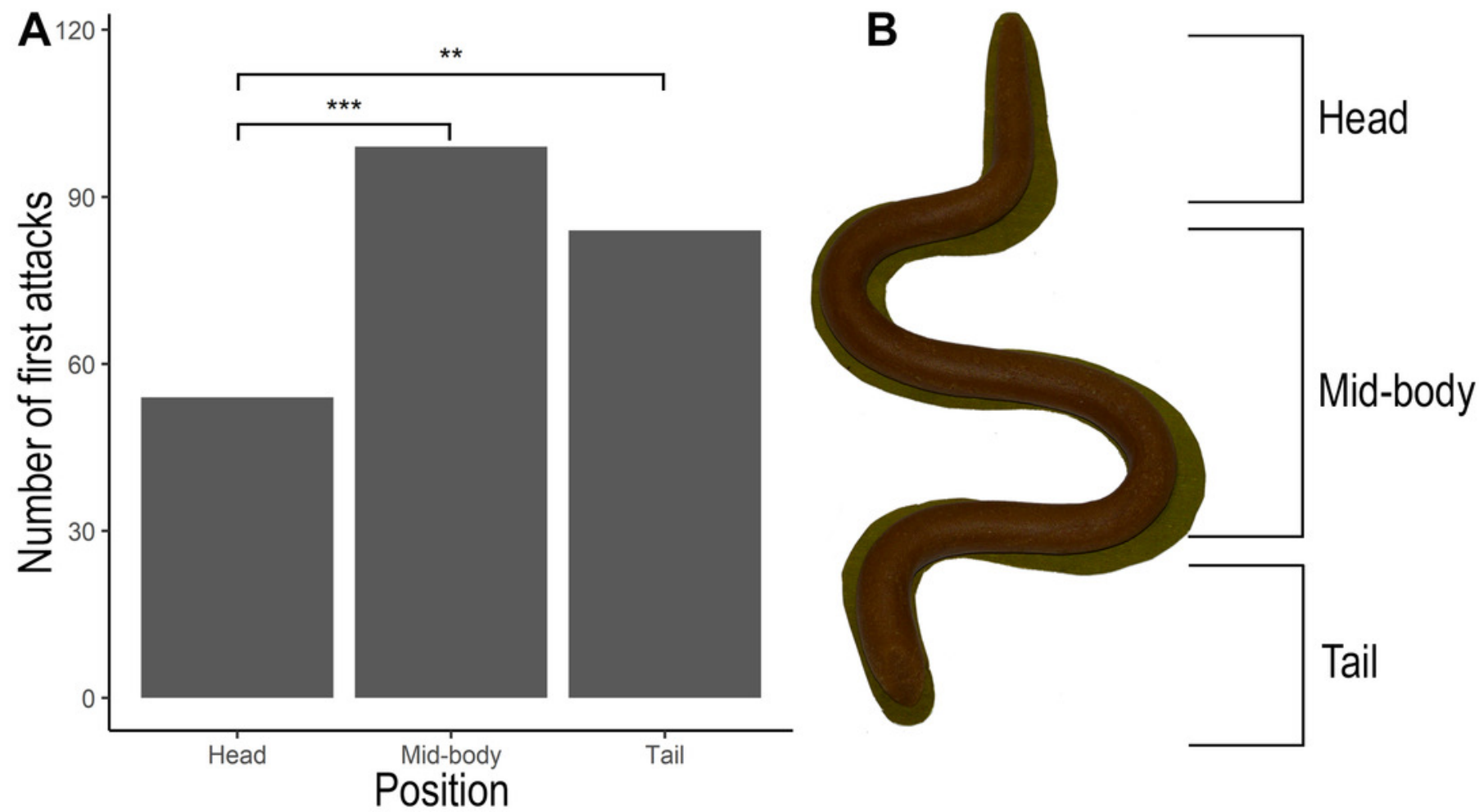